Published in final edited form as:

Soc Sci Med. 2015 November ; 145: 115-119. doi:10.1016/j.socscimed.2015.09.020.

\title{
Happiness and Longevity in the United States
}

\author{
Elizabeth M. Lawrence, PhD, \\ Richard G. Rogers, PhD, and \\ University of Colorado Boulder \\ Tim Wadsworth, PhD \\ University of Colorado Boulder
} University of North Carolina at Chapel Hill

\begin{abstract}
This is the first study to our knowledge to examine the relationship between happiness and longevity among a nationally representative sample of adults. We use the recently-released General Social Survey-National Death Index dataset and Cox proportional hazards models to reveal that overall happiness is related to longer lives among U.S. adults. Indeed, compared to very happy people, the risk of death over the follow-up period is $6 \%$ (95\% CI $1.01-1.11$ ) higher among individuals who are pretty happy and $14 \%$ (95\% CI $1.06-1.22)$ higher among those who are not happy, net of marital status, socioeconomic status, census division, and religious attendance. This study provides support for happiness as a stand-alone indicator of well-being that should be used more widely in social science and health research.
\end{abstract}

\section{Keywords}

happiness; mortality; life expectancy; survival; longevity; GSS-NDI

\section{INTRODUCTION}

Academic interest in the study of happiness has burgeoned over the past twenty years.

Research has established patterns of happiness across personal characteristics and behaviors, such as income (Easterlin 1973, 2001, 2003; Graham and Pettinato 2002), marital status (Haring-Hidore et al. 1985; Veenhoven 1994; Wadsworth 2015), educational achievement (Blanchflower and Oswald 2004), religious faith (Witter et al. 1985), physical health (Dolan et al. 2008), and sexual activity (Blanchflower and Oswald 2004; Wadsworth 2013). In addition to examining the causes of happiness, researchers are increasingly turning their focus to the consequences of happiness, particularly on health and mortality, the focus of this paper.

Extant research suggests that being happy may be associated with better health and longevity (Diener and Chan 2011; Veenhoven 2008). However, many of the studies

An earlier version of this paper was presented at the annual meeting of the Southern Demographic Association on October 12, 2012 in Williamsburg, Virginia. 
supporting these relationships utilized small, geographically specific, and often age-limited samples (Veenhoven 2008). For example, drawing on data from the Nun Study (a longitudinal study of over 600 Catholic nuns of the School Sisters of Notre Dame), Danner and her research team (2001) found that the use of positive emotional language to describe early life experiences in short autobiographies written when the nuns were in their early twenties correlated strongly with longevity fifty to seventy years later. In looking at the writings of over 800 Mayo Clinic patients, Maruta and colleagues (2000) reached similar findings: subjects who described life events using more optimistic language were more likely to survive the thirty-year follow-up period.

A number of physiological mechanisms might explain findings such as these. Happiness appears to be inversely related to perceived stress (Schiffrin and Nelson 2010) and may protect against illness through better immune response (Veenhoven 2008). Happy people typically enjoy better health outcomes because they demonstrate more successful adaptation; better problem-solving skills and coping strategies; more creative, imaginative, and integrative thinking; greater resilience; and a greater ability to deal with adversity (Fredrickson 2003; Ostir et al. 2006). But, as noted, the studies conducted this far have used small, restricted samples, and thus cannot be applied to populations generally. Much of the extant work has also failed to control for important factors that may influence both happiness and longevity.

In particular, we do not yet know the extent to which the potential health benefits of happiness are due to socioeconomic or social resources. Higher levels of subjective wellbeing are also related to increased success in a variety of domains, including social relations and economic stability. Perhaps the most consistent finding has been that happy people usually have stronger social support networks as evidenced by more friends (Staw et al. 1994) and a higher likelihood of marriage (Lucas et al. 2003; Marks and Fleming 1999).

Happier people also tend to make more money. While it may be argued that higher income can also lead to happiness, Marks and Fleming (1999) and Diener and Seligman (2002) found that happiness or cheerfulness at time one significantly increased earnings at time two, up to fifteen years later. It may be that these socioeconomic and social resources explain why happier people have better health. But a recent study shows the effect of happiness on self-rated health is largely independent of marital status, education, income, and socioeconomic resources (Zajacova and Dowd 2014). Sabatini (2008) also finds that the effect of happiness on health is independent of socioeconomic status among Italians.

However, no study has examined these relationships and processes among U.S. adults. In the current work we analyze the relationship between happiness and mortality among a large nationally representative group of U.S. adults while controlling for a variety of economic, social, and demographic factors.

\section{METHODS}

\section{Data}

We use the General Social Survey-National Death Index (GSS-NDI) dataset, which links GSS waves from 1978 to 2002 to mortality information from the NDI through 2008 (Muennig et al. 2011a; NORC 2011). The GSS represents a national sample of English- 
speaking noninstitutionalized individuals ages 18 and over, and provides a wealth of information on their behaviors and attitudes. Over the 18 waves, the GSS survey response rates ranged from $70 \%$ to $82 \%$ (Muennig et al. 2011b).

The GSS-NDI sample includes 32,830 individuals, 9,271 of whom died over the follow-up period. Of this original sample, 32,779 individuals have complete and valid information on age, mortality status, and, for those who died during the follow-up period, age at death. Of this second group, 1,298 individuals are missing information on general happiness because one version of the 2002 survey did not administer the general happiness question; half of the 2002 sample received the question (1,285 individuals) and half did not (1,298 individuals). These individuals who did not receive the happiness question are listwise deleted, leaving a sample of 31,481 people.

\section{Measures}

Our outcome is risk of death over time. Those dying in the follow-up coded 1 and those surviving to 2008 coded 0 . Mortality is an especially important outcome because it is a highly valued measure of health, is accurately measured and reported, is not plagued with some of the problems related to self-reported health measures, and does not suffer biases associated with reverse causality. Because mortality is a rare event, we follow convention and pool multiple years of the GSS and use a long follow-up period. Long follow-up periods are valuable for outcome variables such as mortality, which may take several years to manifest (see, for example, Peterson et al. [1988]). To link mortality information to the respondents, the NDI uses a matching algorithm based on a set of identifiers, such as social security number and first and last name (Muennig et al. 2011a).

Our main independent variable of interest is happiness. Each wave of the GSS asks the following question: "Taken all together, how would you say things are these days-would you say that you are very happy, pretty happy, or not too happy?" We coded the response categories for this variable into dummy variables, with very happy omitted as the reference group. The distribution of the response categories for this variable is fairly consistent across time.

It is important to determine whether the relationship between happiness and mortality persists even with controls for other factors, such as sex, race, marital status, socioeconomic status, region, and religiosity. As such, all multivariate models control for sex, with female as the referent, and race, with white as the referent. Marital status is coded as widowed, divorced, or never married, with married as the referent.

Educational attainment, income, and employment status are three classic measures of socioeconomic status. Educational attainment is recoded to four categories: the reference group of less than high school, high school diploma, more than high school, and college degree or higher. The categorical income variable represents whether the ratio of one's income to the threshold of poverty is below $100 \%$ (referent), 100-199\%, 200-299\%, or $300 \%$ or above. The income-to-needs ratios were calculated by recoding the categorical income variable to its midpoint, and then dividing that value by the U.S. Census threshold for poverty for the specific year and household size. Employment status is coded into eight 
different categories, with the reference group of full-time workers compared to part-time workers, those temporarily not working, unemployed individuals, retirees, students, those keeping house, and individuals reporting other employment status.

The categorical division variable represents nine U.S. census divisions: New England, Middle Atlantic, East North Central, West North Central, South Atlantic, East South Central, West South Central, Pacific, and Mountain (the referent and the division with the smallest percentage of deaths). Religious involvement is indicated through four categories of religious attendance, defined in accordance with previous studies (Hummer et al. 1999): never attending religious services, attending services less than once a week, attending services once a week, and attending services more than once a week (referent).

\section{Analytic Strategy}

To determine the relationship between happiness and the risk of death, we use Cox proportional hazards models. The Cox models use age at interview as the time variable, and the duration is calculated as the time from the interview to death or 2008, the end of the follow-up period. The inclusion of this duration controls for variation in the amount of time between the respondent's report of happiness and his or her death or the end of the followup period. We use the Efron method for handling failure ties, which produces more accurate approximations of the exact marginal (Hertz-Picciotti and Rockhill 1997).

We use multiple imputation to handle item missingness. No individuals were missing on gender, race, employment status, division, or the GSS variable representing whether an individual was part of an oversample. Four values were imputed for marital status, 271 values for happiness, 73 for education, 2,989 for income-to-needs, and 392 for religious attendance. We used a fully conditional specification approach, creating 10 datasets. All independent and dependent variables informed imputation, as well as an auxiliary variable representing if the individual grew up with two biological parents.

We first look at the relationship between general happiness and mortality, starting with a base model that includes happiness categories, sex, and race (and accounts for age within the duration variable), and then add other covariates to determine their effect on mortality and the influence of happiness net of these other factors. All models include the oversampling variable provided by the GSS, making the sample nationally representative.

Robustness Checks-We obtained similar results with different follow-up periods, including right censoring at 15 and 20 years of follow-up, and with more recent samples that eliminated the first 5 or 10 years of survey respondents. Tests of proportionality indicate that the variable of interest exhibits proportional hazards, which satisfies a central assumption of hazards analysis. Further, terms interacting happiness with birth cohort or year of interview produced no significant values. Prior research has established patterns of happiness across ages, periods, and cohorts (Blanchflower and Oswald 2008; Yang 2008), but the effect of happiness on mortality does not appear to differ across the life course. Overall, these sensitivity tests demonstrate that the results presented here are stable and robust. 


\section{RESULTS}

Table 1 shows general happiness by demographic, social, economic, and health characteristics. About a third (31.4\%) of the adult population is very happy, over half (56.9\%) is pretty happy, and $11.6 \%$ is not happy. Individuals who report being very happy are more common among those who are older, white, married, and more educated; those with higher incomes; and those who attend religious services. Yet, even in disadvantaged groups, only small proportions report being not happy. For example, among those in poverty (income-to-needs is less than 100\%), 21.2\% report they are not happy. Because these descriptive statistics do not control for other covariates, we turn to the multivariate models in Table 2.

Table 2 demonstrates a strong graded relationship between happiness and the risk of death. Compared to those who are very happy, those who are pretty happy have $7 \%$ higher risk of death (hazards ratio $[\mathrm{HR}]=1.07$ ), and those who are not happy are $21 \%$ more likely to die over the follow-up period, when sex and race are controlled (Model 1). The relationship between happiness and mortality attenuates slightly but remains significant with controls for marital status (Model 2), socioeconomic status (education, income, and employment [Model 3]), geographical divisions (Model 4), and religious attendance (Model 5). The largest reduction in the increased mortality risk for those not happy occurs with the addition of the socioeconomic variables (compare Models 2 and 3).

Because happiness is strongly related to marital status (Haring-Hidore et al. 1985; Veenhoven 1994; Wadsworth 2015), we tested for but did not find a significant interactive effect of happiness and marital status on mortality. We found no significant interactions between happiness and each of the other covariates-sex, race, education, income, employment, census divisions, and religious attendance—on mortality. We also examined whether the results were robust to health status through running the same models on a subsample of individuals who reported good or excellent health. In these models, the "pretty happy" hazard ratio does not differ significantly from one and the ratios for "not happy" are attenuated compared to the models presented here. These results suggest that happiness and health status are correlated, but further interpretation is unclear because the measures were collected at the same time and self-rated health can reflect a wide variety of conditions. Additionally, statistical power is reduced because we omit those who report fair or poor health and those who are not asked about self-rated health, resulting in a sample size $55 \%$ of the original sample.

\section{DISCUSSION}

Happy people live longer. Compared to very happy people, the risk of death over the followup period is $6 \%$ higher among those who are pretty happy and 14\% higher among those who are not happy (Table 2, Model 5), even after controlling for an array of demographic, socioeconomic, and lifestyle-related factors. Happiness is related to other risk factors, including social relations, socioeconomic status, census division, and religious attendance, and its effect on life expectancy may operate in part through stronger social relationships and increased socioeconomic status (Fredrickson 2003; Ostir et al. 2006). Happiness appears 
to permeate through all walks of life, perhaps in reciprocal relationships with these other factors. For example, marriage selects happy people and then provides social support and material resources that further contribute to happiness (Carr and Springer 2010; Lucas et al. 2003; Marks and Fleming 1999).

Happiness is also independent of other factors. The increased mortality risk for less happy individuals attenuated somewhat but remained significant. Further, we found no significant interactions between happiness and the other covariates. That is, mortality risk is lower for happy than unhappy individuals, and for married than unmarried individuals, but there is no additional longevity benefit for people who are both happy and married. Happiness thus appears to capture a meaningful subjective perspective on well-being that cannot be accounted for with more objective indicators of socioeconomic and social resources.

The GSS-NDI is a wonderful new prospective dataset that provides a rich set of variables. Because this cross-sectional dataset does not collect information on time-varying covariates, future studies could use other data sources to examine whether changes in happiness are associated with the risk of death. Still, we find that the level of happiness reported at the time of the interview is related to the risk of death years later.

This study provides support for happiness as a stand-alone indicator of well-being that can be used in more social science and health research. Future research should seek to distinguish when and how happiness improves health and longevity. For example, identifying associations between more specific conceptualizations of psychological functioning and mortality may reveal the processes through which well-being shapes health (or health shapes well-being). Further, while we did not find differences in the influence of happiness on mortality, there may be other processes that differ. For example, Muennig et al. (2013) find that existential satisfaction explains some of the income-mortality relationship for women but not men.

Economists are concerned with economic security, criminologists with safety and violence prevention, and public health advocates with unhealthy behaviors. We miss an important variable if we overlook happiness. Higher incomes, crime-free neighborhoods, and improved public health programs may provide security, safety, and reduced disease, but they do not necessarily engender happiness. In addition to improving a population's economic standard of living, access to medical care, and healthy behaviors, policymakers should consider ways to make people happy, which may involve more community engagement; more city beautification projects; ways to help people manage stress and to relax; and encouraging strong, lasting, positive social ties among friends, neighbors, and families, including spouses. Happiness may provide a route toward more enjoyable and longer lives.

\section{Acknowledgments}

We thank the Eunice Kennedy Shriver National Institute of Child Health and Human Development (NICHD)funded University of Colorado Population Center (Award Number R24HD066613) for administrative and computing support; Columbia University, Mailman School of Public Health, and NORC at the University of Chicago for collecting the data and making the linked files available to the research public; and Nancy Mann for insightful edits and comments on an earlier draft of this paper. The content of this manuscript is solely the responsibility of the authors and does not necessarily represent the official views of the NICHD or the National Institutes. 


\section{References}

Blanchflower DG, Oswald AJ. Well-being over time in Britain and the USA. Journal of Public Economics. 2004; 88(7-8):1359-1386.

Blanchflower DG, Oswald AJ. Is well-being U-shaped over the life cycle? Social Science \& Medicine. 2008; 66(8):1733-1749. [PubMed: 18316146]

Carr D, Springer KW. Advances in families and health research in the 21 st century. Journal of Marriage and Family. 2010; 72(3):743-761.

Danner DD, Snowdon DA, Friesen WV. Positive emotions in early life and longevity: Findings from the nun study. Journal of Personality and Social Psychology. 2001; 80(5):804-813. [PubMed: 11374751]

Diener E, Chan MY. Happy people live longer: Subjective well-being contributes to health and longevity. Applied Psychology: Health and Well-Being. 2011; 3(1):1-43.

Diener E, Seligman MEP. Very happy people. Psychological Science. 2002; 13(1):81-84. [PubMed: 11894851]

Dolan P, Peasgood T, White M. Do we really know what makes us happy? A review of the economic literature on the factors associated with subjective well-being. Journal of Economic Psychology. 2008; 29(1):94-122.

Easterlin RA. Does money buy happiness? The Public Interest. 1973; 30(10)

Easterlin RA. Income and happiness: Towards a unified theory. The Economic Journal. 2001; 111(473):465-484.

Easterlin RA. Explaining happiness. Proceedings of the National Academy of Sciences. 2003; 100(19): 11176-11183.

Fredrickson B. The value of positive emotions. American Scientist. 2003; 91(4)

Graham C, Pettinato S. Frustrated achievers: Winners, losers and subjective well-being in new market economies. Journal of Development Studies. 2002; 38(4):100-140.

Haring-Hidore M, Stock WA, Okun MA, Witter RA. Marital status and subjective well-being: A research synthesis. Journal of Marriage and Family. 1985; 47(4):947-953.

Hertz-Picciotto I, Rockhill B. Validity and efficiency of approximation methods for tied survival times in Cox regression. Biometrics. 1997:1151-1156. [PubMed: 9333345]

Hummer R, Rogers R, Nam C, Ellison C. Religious involvement and U.S. adult mortality. Demography. 1999; 36(2):273-285. [PubMed: 10332617]

Lucas RE, Clark AE, Georgellis Y, Diener E. Reexamining adaptation and the set point model of happiness: Reactions to changes in marital status. Journal of Personality and Social Psychology. 2003; 84(3):527-539. [PubMed: 12635914]

Marks GN, Fleming N. Influences and consequences of well-being among Australian young people: 1980-1995. Social Indicators Research. 1999; 46(3):301-323.

Maruta T, Colligan RC, Malinchoc M, Offord KPCMCP. Optimists vs pessimists: survival rate among medical patients over a 30-year period. 2000

Muennig P, Johnson G, Kim J, Smith TW, Rosen Z. The general social survey-national death index: an innovative new dataset for the social sciences. BMC Research Notes. 2011a; 4(1)

Muennig P, Kuebler M, Kim J, Todorovic D, Rosen Z. Gender differences in material, psychological, and social domains of the income gradient in mortality: implications for policy. PloS One. 2013; $8(3)$

Muennig P, Johnson G, Kim J, Smith TW, Rosen Z. The general social survey-national death index: an innovative new dataset for the social sciences. BMC Research Notes. 2011a; 4(1)

Muennig, P.; Rosen, Z.; Blaylock, T.; Johnson, G.; Smith, T.; Kim, J. GSS-NDI Codebook: Program in Cost-Effectiveness and Outcomes (PCEO). $2011 \mathrm{~b}$.

National Opinion Research C. GSS-NDI 1978-2002. 2011. Retrieved from http://www3.norc.org/GSS +Website/Download/

Ostir GV, Berges IM, Markides KS, Ottenbacher KJ. Hypertension in older adults and the role of positive emotions. Psychosomatic Medicine. 2006; 68(5):727-733. [PubMed: 17012526] 
Peterson C, Seligman ME, Vaillant GE. Pessimistic explanatory style is a risk factor for physical illness: A thirty-five-year longitudinal study. Journal of Personality and Social Psychology. 1988; 55(1):23-27. [PubMed: 3418489]

Sabatini F. The relationship between happiness and health: evidence from Italy. Social Science \& Medicine. 2014; 114:178-187. [PubMed: 24934667]

Schiffrin H, Nelson S. Stressed and happy? Investigating the relationship between happiness and perceived stress. Journal of Happiness Studies. 2010; 11(1):33-39.

Staw BM, Sutton RI, Pelled LH. Employee positive emotion and favorable outcomes at the workplace. Organization Science. 1994:51-71.

Veenhoven, R. World database of happiness: Correlates of happiness: 7837 findings from 603 studies in 69 nations 1911-1994. Vol. 1-3. Rotterdam, Netherlands: Erasmus University Rotterdam; 1994.

Veenhoven R. Healthy happiness: effects of happiness on physical health and the consequences for preventive health care. Journal of Happiness Studies. 2008; 9(3)

Wadsworth T. Marriage and subjective well-being: How and why context matters. Social Indicators Research. 2015 Online First.

Wadsworth T. Sex and the pursuit of happiness: How other people's sex lives are related to our sense of well-being. Social Indicators Research. 2014; 116:115-135.

Witter RA, Stock WA, Okun MA, Haring MJ. Religion and subjective well-being in adulthood: A quantitative synthesis. Review of Religious Research. 1985; 26(4):332-342.

Yang Y. Social inequalities in happiness in the United States, 1972 to 2004: An age-period-cohort analysis. American Sociological Review. 2008; 73(2):204-226.

Zajacova A, Dowd JB. Happiness and health among US working adults: is the association explained by socio-economic status? Public Health. 2014; 9(128):849-851. [PubMed: 25174664] 
TABLE 1

Percentages of Happiness Level by Subgroup Among U.S. Adults, 1978-2002 (N=31,481)

\begin{tabular}{|c|c|c|c|}
\hline & \multicolumn{3}{|c|}{ General Happiness } \\
\hline & Very Happy & Pretty Happy & Not Happy \\
\hline Overall population & $31.4 \%$ & $56.9 \%$ & $11.6 \%$ \\
\hline \multicolumn{4}{|l|}{ Age } \\
\hline $18-44$ & $29.4 \%$ & $59.4 \%$ & $11.2 \%$ \\
\hline $45-64$ & $32.9 \%$ & $54.9 \%$ & $12.2 \%$ \\
\hline 65 and above & $35.6 \%$ & $52.5 \%$ & $11.9 \%$ \\
\hline \multicolumn{4}{|l|}{ Sex } \\
\hline Male & $31.3 \%$ & $57.5 \%$ & $11.1 \%$ \\
\hline Female & $31.5 \%$ & $56.5 \%$ & $12.0 \%$ \\
\hline \multicolumn{4}{|l|}{ Race } \\
\hline White & $33.2 \%$ & $56.8 \%$ & $10.0 \%$ \\
\hline Black & $21.6 \%$ & $58.3 \%$ & $20.1 \%$ \\
\hline Other race & $29.9 \%$ & $55.4 \%$ & $14.7 \%$ \\
\hline \multicolumn{4}{|l|}{ Marital Status } \\
\hline Married & $40.2 \%$ & $52.9 \%$ & $6.9 \%$ \\
\hline Widowed & $24.7 \%$ & $57.2 \%$ & $18.2 \%$ \\
\hline Divorced & $18.7 \%$ & $62.0 \%$ & $19.3 \%$ \\
\hline Never married & $22.8 \%$ & $62.9 \%$ & $14.3 \%$ \\
\hline \multicolumn{4}{|l|}{ Education } \\
\hline Less than High School & $28.3 \%$ & $53.9 \%$ & $17.7 \%$ \\
\hline High School & $30.2 \%$ & $58.5 \%$ & $11.3 \%$ \\
\hline Some college & $31.2 \%$ & $58.9 \%$ & $9.9 \%$ \\
\hline College degree & $37.0 \%$ & $55.7 \%$ & $7.4 \%$ \\
\hline \multicolumn{4}{|l|}{ Employment } \\
\hline Full time & $31.5 \%$ & $59.3 \%$ & $9.2 \%$ \\
\hline Part time & $30.4 \%$ & $58.4 \%$ & $11.2 \%$ \\
\hline Temp not working & $28.2 \%$ & $57.9 \%$ & $13.9 \%$ \\
\hline Unemployed, laid off & $18.5 \%$ & $52.7 \%$ & $28.8 \%$ \\
\hline Retired & $34.7 \%$ & $53.1 \%$ & $12.2 \%$ \\
\hline School & $29.7 \%$ & $58.6 \%$ & $11.7 \%$ \\
\hline Keeping house & $33.7 \%$ & $52.4 \%$ & $13.9 \%$ \\
\hline Other & $20.5 \%$ & $50.8 \%$ & $28.8 \%$ \\
\hline \multicolumn{4}{|l|}{ Income-to-needs } \\
\hline Less than $100 \%$ & $22.0 \%$ & $56.7 \%$ & $21.2 \%$ \\
\hline $100-199 \%$ & $29.2 \%$ & $57.8 \%$ & $13.0 \%$ \\
\hline $200-299 \%$ & $34.6 \%$ & $57.3 \%$ & $8.1 \%$ \\
\hline $300 \%$ or more & $36.0 \%$ & $55.7 \%$ & $8.3 \%$ \\
\hline \multicolumn{4}{|l|}{ Census Division } \\
\hline New England & $32.0 \%$ & $58.4 \%$ & $10.0 \%$ \\
\hline
\end{tabular}




\begin{tabular}{lccr}
\hline & \multicolumn{3}{c}{ General Happiness } \\
\cline { 2 - 4 } & Very Happy & Pretty Happy & Not Happy \\
\hline Middle Atlantic & $27.9 \%$ & $57.9 \%$ & $14.1 \%$ \\
East North Central & $30.8 \%$ & $57.0 \%$ & $12.2 \%$ \\
West North Central & $31.3 \%$ & $60.8 \%$ & $7.9 \%$ \\
South Atlantic & $33.5 \%$ & $54.9 \%$ & $11.6 \%$ \\
East South Central & $33.6 \%$ & $54.5 \%$ & $11.9 \%$ \\
West South Central & $31.7 \%$ & $56.4 \%$ & $11.9 \%$ \\
Mountain & $31.7 \%$ & $58.1 \%$ & $10.2 \%$ \\
Pacific & $31.5 \%$ & $56.8 \%$ & $11.6 \%$ \\
Religious Attendance & & & \\
Never & $25.1 \%$ & $58.0 \%$ & $16.9 \%$ \\
Less than once a week & $28.7 \%$ & $59.5 \%$ & $11.8 \%$ \\
Once a week & $38.3 \%$ & $53.5 \%$ & $8.2 \%$ \\
Greater than once a week & $46.3 \%$ & $45.1 \%$ & $8.6 \%$ \\
\hline
\end{tabular}

Source: GSS-NDI 


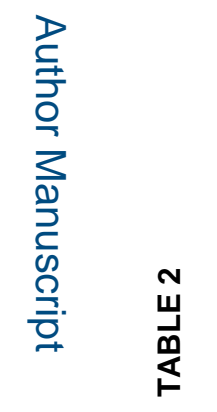

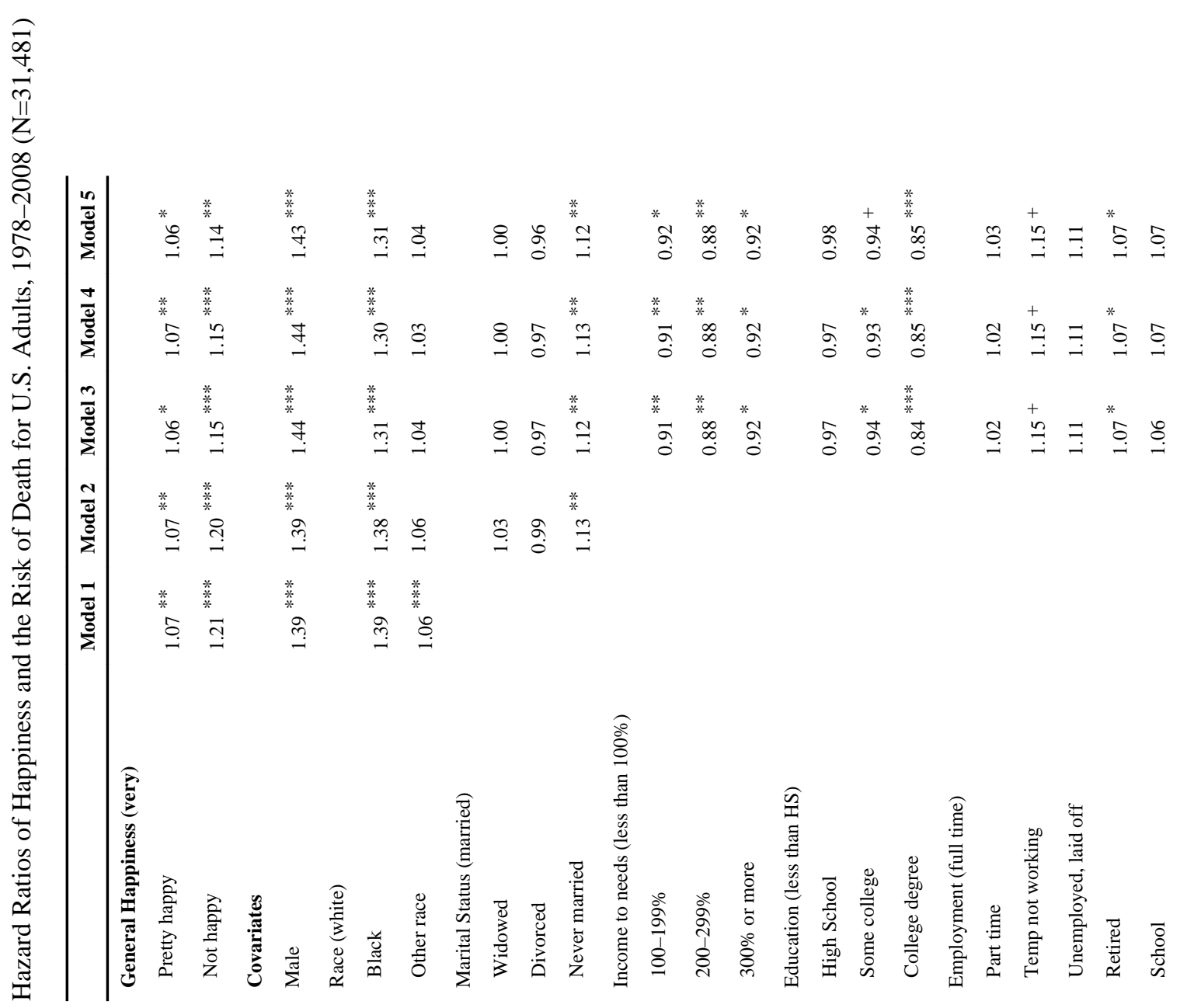


후

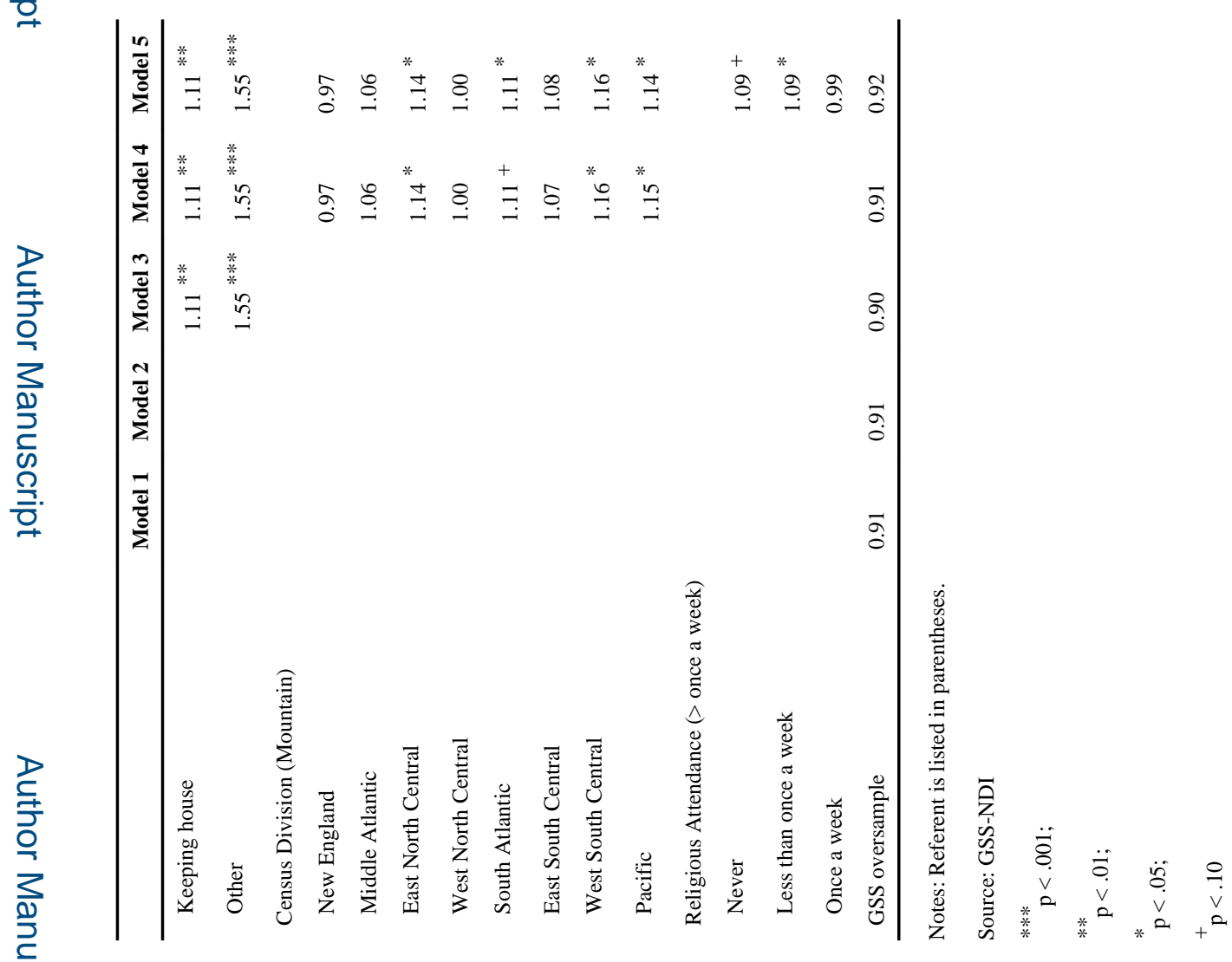

Soc Sci Med. Author manuscript; available in PMC 2016 November 01. 